\title{
Complications of prosthetic intraocular lens implantation: a histopathological study
}

\author{
ALEC GARNER \\ From the Department of Pathology, Institute of Ophthalmology, University of London
}

SUMmARY A total of 104 eyes and 43 resected corneal discs from patients with failed intraocular lens implants (IOL) received over a period of 35 years were subjected to histopathological analysis. Eyes collected at necropsy from 18 people with clinically successful implants were also examined. Corneal decompensation leading to bullous keratopathy was the most frequent reason for failure, followed by glaucoma and intraocular inflammation. Of 18 cases in which inflammation was the principal clinical cause of failure 12 presented as infectious endophthalmitis, but minor degrees of sterile uveitis were fairly common. Retinal detachment was seen in seven cases. The interval between IOL implantation and the onset of serious complications varied from one month to 29 years, indicating that the presence of prosthesis will always entail a latent risk of an adverse tissue response, albeit slight.

From rather shaky beginnings the principles and techniques of intraocular lens (IOL) implantation have developed to the level that replacement of the defective lens with a prosthesis is now seen to be the preferred way of dealing with eyes undergoing cataract surgery. Other than in children the limitations on the use of IOLs have more to do with availability and economic restraints than with surgical considerations, and yet there is a significant morbidity associated with their insertion which should not be ignored. Already a substantial number of histopathological reports of the untoward effects of IOLs has been reported and have been well reviewed by Apple and his colleagues. ${ }^{1}$ McDonnell, Green, and Champion ${ }^{2}$ identified at least 25 complications in eyes that had undergone apparently successful IOL insertion. The object of the present report is to describe our experience at the Institute of Ophthalmology in the University of London with reference to eyes wherein the prosthetic insertion was mostly unsuccessful.

\section{Materials and methods}

Over the period 1953-88 we received 104 eyes from 102 patients and 43 corneal discs (Table 1). Eighteen

Correspondence to Professor A Garner, Institute of Ophthalmology, 17-25 Cayton Street, London EC1V 9AT. of the eyes had undergone successful procedures; all but one of the eyes were obtained post mortem. But the remainder, apart from three eyes which had received implants less than 10 days before death, represented failed implants. Two of the visually successful cases have been reported separately on earlier occasions. ${ }^{34}$ The lone eye with a visually successful implant obtained in life was from a patient found to have a malignant melanoma of the choroid some two years later. One hundred and six of the IOLs had been positioned in the anterior chamber (mostly variants of the Choyce and Fyodorov lenses), 14 were iris-clip lenses, and 12 were in the posterior chamber. The available clinical information, particularly in respect of the earlier cases, was inadequate to allow meaningful distinction between cases preceded by intracapsular as opposed to extracapsular cataract extraction.

The specimens were fixed and processed in a conventional manner prior to embedding, sectioning,

Table 1 Histology of IOL implants 1953-88

\begin{tabular}{llllc}
\hline & Successful & Failed & Other & Total \\
\hline Eyes & 18 & 83 & 3 & 104 \\
Corneal discs & 0 & 43 & 0 & 43 \\
Total & 18 & 126 & 3 & 147 \\
& $(12 \cdot 2 \%)$ & $(85 \cdot 7 \%)$ & $(2 \cdot 04 \%)$ & $(100 \%)$ \\
\hline
\end{tabular}


Table 2 Successful IOL implant procedure

\begin{tabular}{llll}
\hline & \multicolumn{2}{l}{ Histological findings } \\
\cline { 2 - 4 } & $\begin{array}{l}\text { Corneal } \\
\text { decompensation }\end{array}$ & $\begin{array}{c}\text { Secondary } \\
\text { glaucoma }\end{array}$ & $\begin{array}{l}\text { Anterior } \\
\text { uveitis }\end{array}$ \\
\hline Anterior (14 eyes) & 1 & 0 & 4 \\
Iris clip (3 eyes) & 0 & 0 & 0 \\
Posterior (1 eye) & 0 & 0 & 0 \\
Total (18 eyes) & 1 & 0 & 4 \\
& $5 \cdot 5 \%$ & $0 \%$ & $22 \cdot 2 \%$ \\
\hline
\end{tabular}

staining, and microscopical examination. In most instances the prostheses were left in situ and dissolved out with chloroform before sectioning, but on some occasions they were removed during the gross examination, with care not to disturb the adjacent tissues more than necessary.

\section{Results}

\section{SUCCESSFUL IOL IMPLANTATION}

Fourteen of the 18 eyes had received anterior chamber lens implants, three iris-clip lenses, and one a posterior chamber implant (Table 2). Evidence of endothelial cell loss, albeit minor, from the back of the cornea was seen in one eye only in relation to an anterior chamber implant, and there was no associated oedema. In that instance the prosthesis had been in position for three years, and to some extent the loss of endothelium might have been a reflection of the patient's advanced age of 92 years.

Erosion of the iris attributable to the haptics and some fibrous tissue proliferation in the anterior chamber, chiefly in relation to the angles, was observed in most eyes, but it was not of a degree that would have been expected to interfere with aqueous drainage to any significant extent. Posterior iris tucks and minor degrees of angle recession were not uncommon in respect of the anterior chamber implants.

Mild diffuse lymphocytic infiltration of the iris was noted in four eyes.

Table 3 Clinical indications of IOL implant failure

\begin{tabular}{|c|c|c|c|c|}
\hline & $\begin{array}{l}\text { Bullous } \\
\text { keratopathy }\end{array}$ & $\begin{array}{l}\text { Secondary } \\
\text { glaucoma }\end{array}$ & $\begin{array}{l}\text { Intraocular } \\
\text { inflammation }\end{array}$ & $\begin{array}{l}\text { Other } \\
\text { problems }\end{array}$ \\
\hline Anterior (92)* & 38 & 32 & 12 & 10 \\
\hline Iris clip (12) & 10 & 1 & 0 & 1 \\
\hline Posterior (10) & 3 & 1 & 5 & 1 \\
\hline $\begin{array}{l}\text { Site unknown } \\
\text { (12) }\end{array}$ & 9 & 2 & 1 & 0 \\
\hline \multirow[t]{2}{*}{ Total (126) } & 60 & & 18 & 12 \\
\hline & $47 \cdot 6 \%$ & $28 \cdot 6 \%$ & $14 \cdot 3 \%$ & $9 \cdot 5 \%$ \\
\hline
\end{tabular}

*Bracketed figures represent combined numbers of enucleated eyes and resected corneal discs.
Table 4 Histological features of failed IOL implant procedures

\begin{tabular}{lllll}
\hline & $\begin{array}{l}\text { Corneal } \\
\text { decompensation }\end{array}$ & Uveitis & $\begin{array}{l}\text { Infectious } \\
\text { endophthalmitis }\end{array}$ & Glaucoma \\
\hline $\begin{array}{c}\text { Anterior } \\
(92)^{*}\end{array}$ & 44 & 38 & 8 & 41 \\
$\begin{array}{c}\text { Iris clip } \\
(12)\end{array}$ & 10 & 1 & 0 & 1 \\
$\begin{array}{c}\text { Posterior } \\
(10)\end{array}$ & 5 & 6 & 3 & 3 \\
$\begin{array}{c}\text { Site } \\
\text { unknown } \\
(12)\end{array}$ & 9 & 3 & 1 & 2 \\
$\begin{array}{c}\text { Total (126) } 68 \\
54.0 \%\end{array}$ & $38 \cdot 1 \%$ & $9 \cdot 5 \%$ & $37 \cdot 3 \%$ \\
\hline
\end{tabular}

*Bracketed figures represent combined numbers of enucleated eyes and resected corneal discs. Infectious endophthalmitis cases are listed as a subdivision of the total uveitis group.

\section{FAILED IOL IMPLANTATION}

The clinical reasons for failure with the corresponding histopathological findings are listed in Tables 3 and 4. In most cases these took the form of bullous keratopathy, glaucoma, or intraocular inflammation, but in a few cases such diverse problems as postimplantation trauma, stromal keratitis, and corneal abscess leading to perforation were implicated.

\section{BULLOUS KERATOPATHY}

Bullous keratopathy was the commonest clinical cause of failure (Fig. 1), presenting in 60 of the 126 cases $(47 \cdot 6 \%)$. So far as could be ascertained from histological examination, there was no evidence of an

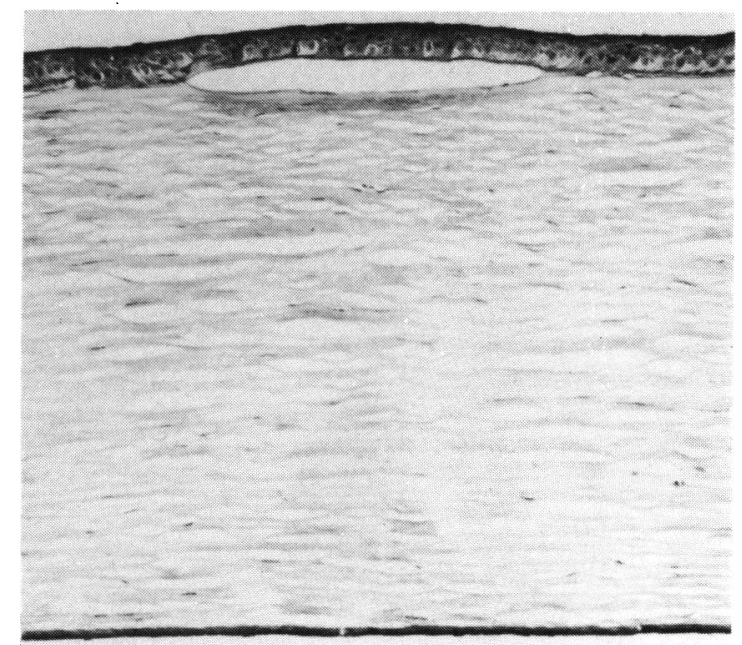

Fig. 1 Bullous keratopathy secondary to an anterior chamber IOL implant. The corneal endothelium is abnormally sparse. (Periodic acid Schiff and haematoxylin, $\times 100$ ). 
alternative explanation, such as Fuch's dystrophy, for the corneal oedema, though in five specimens (four related to anterior and one to posterior chamber implants) there were signs of concurrent stromal inflammation. Four of the resected corneas were associated with retrocorneal membranes (three anterior chamber prostheses and one of unknown placement). Clearly enucleation would not be entertained for isolated corneal disturbance, but in several instances this was a major component of the patients' complaints in conjunction with such lesions as anterior chamber fibrosis and glaucoma. Thus some 18 enucleation specimens were reported to have bullous keratopathy on clinical grounds, while histological examination revealed significant endothelial cell atrophy and loss in 28 of the 83 eyes, giving a combined incidence of corneal decompensation for eyeballs and resected corneal discs of $55 \cdot 6 \%$.

\section{G LA U COMA}

Secondary closed angle was the next most frequent complication in the unsuccessful implant procedures, being the principal problem in 36 of the 126 cases $(28 \cdot 6 \%)$. However, histological inspection indicated that there was evidence of choroidoretinal atrophy and cupping of the optic nerve head consistent with clinically raised intraocular pressure in another 11 eyes, to give an overall incidence of $37 \cdot 3 \%$. One of the most frequent underlying tissue changes was extensive fibrosis within the anterior chamber (Figs. 2 and 3), often appearing to have derived from the cornea and rarely enveloping the IOL to form a pseudocapsule. A second common finding was of corneoirideal adhesions, which were sometimes

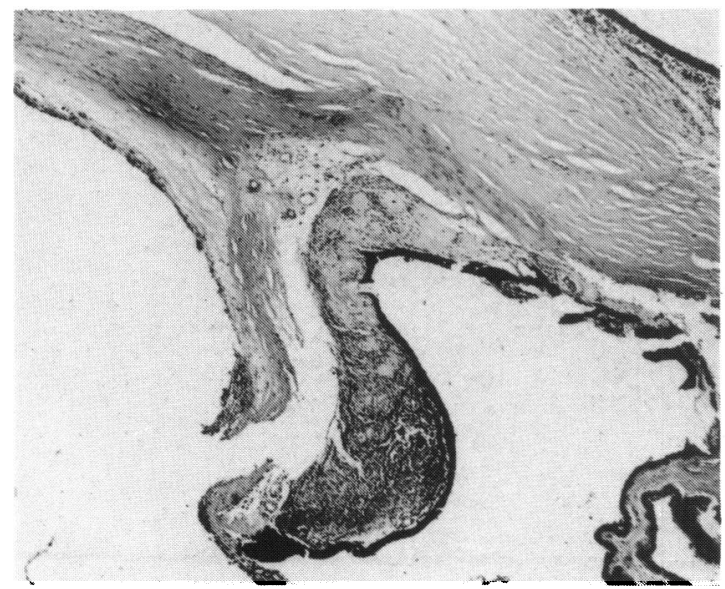

Fig. 2 Dense, partly vascularised, retrocorneal fibrous tissue obliterating the filtration angle in response to an anterior chamber IOL inserted five years earlier. There is also posterior tucking of the iris. ( $H$ and $E, \times 26)$.

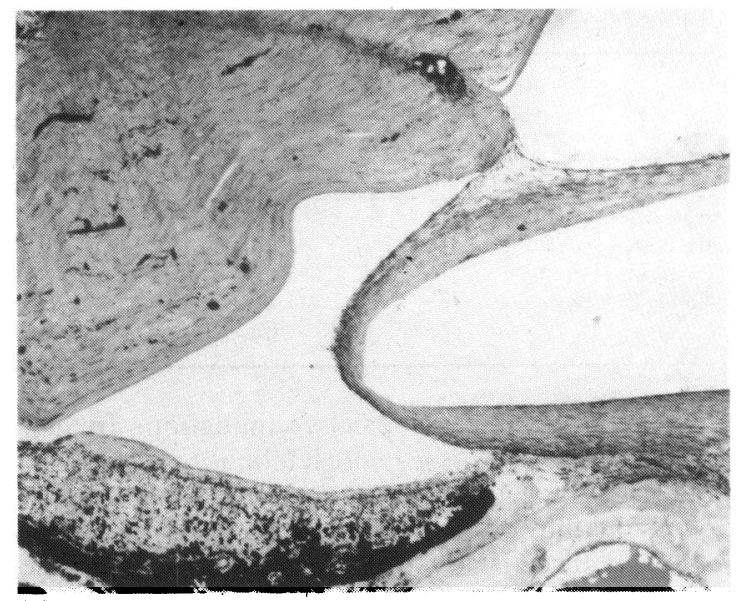

Fig. 3 The anteriorly located IOL is surrounded by fibrous tissue which appears to have emanated from the cornea at the site of the lensectomy scar. A fibrous membrane is also present on the surface of the iris, and there is a retinal detachment. ( $H$ and $E, \times 26)$.

associated with rubeosis iridis in the presence of chronic retinal detachment. Occasionally interference with aqueous outflow was attributable to epithelialisation (five cases) (Fig. 4) and, exceptionally, to descemetisation (one case) of the anterior chamber. In some instances, particularly where there had been repeated surgical intervention, it was not possible to determine the basis of the glaucoma.

\section{INFLAMMATION}

Clinically diagnosed endophthalmitis, occurring

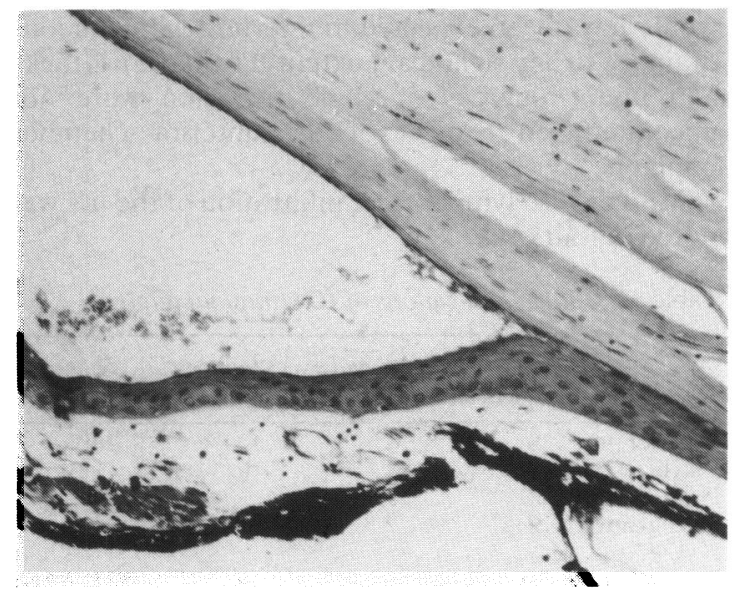

Fig. 4 Squamous epithelium is covering the surface of the iris and occluding the filtration angle secondary to an anterior chamber IOL introduced two years before. ( $H$ and $E, \times$ 110). 


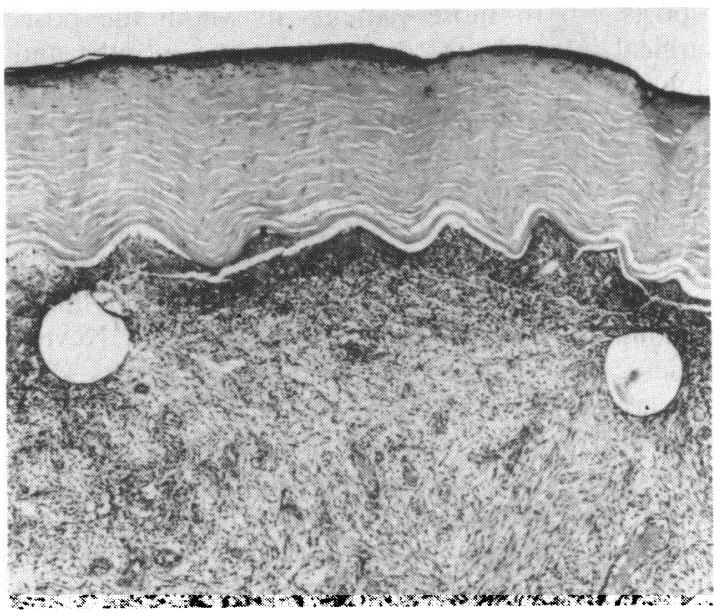

Fig. 5 Endophthalmitis with partially organised purulent exudate filling the anterior chamber and surrounding the haptics of an anterior IOL present for two months. ( $H$ and $E$, $\times 26)$.

between six days and 46 months after IOL implantation, was the reason for enucleation in 12 instances (Fig. 5). Bacterial infection was implicated in all but one patient, from whom a fungus was isolated; in that instance infection with Trichosporon beigelii developed nine months after insertion of an anterior chamber IOL. Minor degrees of anterior uveitis, chiefly in the form of diffuse lymphocytic infiltration of the iris, were identified in a further 36 eyes. Presumed non-infective uveitis was the presenting clinical problem in six other patients, raising

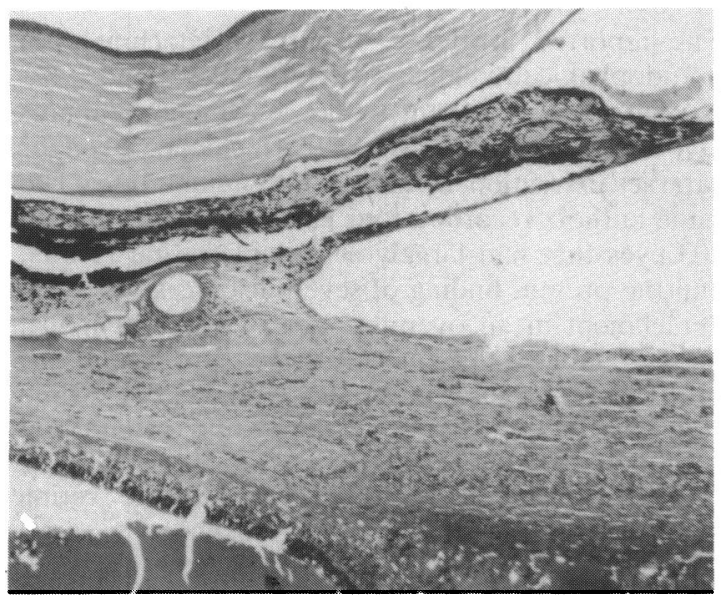

Fig. 6 Retinal detachment in the presence of a fibrovascular cyclitic membrane and a posterior chamber IOL. There is also forward displacement of the iris and an extremely shallow anterior chamber. ( $H$ and $E, \times 26)$. suspicions of impending sympathetic ophthalmitis in one. Altogether intraocular inflammation of all grades of severity was noted histologically in 48 eyes but only in $18(14.3 \%$ of the series overall and $37.5 \%$ of the globes with demonstrable uveitis) was it the presenting condition.

\section{RETINAL DETACHMENT}

Total or subtotal detachment of the retina was observed in seven eyes (Fig. 6). Five of them had had anterior chamber and two of them posterior chamber implants.

\section{Discussion}

DURATION OF IMPLANTS

The length of time between insertion of the IOLs and examination of the eyeballs in patients with wholly successful implants varied widely from two months to 17 years (average 3 years 8 months), while, where the information was available, the interval in those with failed procedures ranged between one month and 25 years (average 5 years 5 months). In a number of instances the IOL was removed some time before enucleation, and in these cases it is the shorter period that has been used for the analysis. The extremely long spells that can be experienced before the situation deteriorates to the level where surgical intervention is required begs the question as to what consitutes a successful IOL procedure: an eye which has tolerated an implant for upwards of 10 years prior to serious complications (14 of the 95 ostensible failures in which the time interval was stated) ought to be accorded at least a measure of success. In nine of those 14 there was evidence of endothelial decompensation. On the other hand it would seem that at no stage is there freedom from the risk that problems will arise.

\section{CORNEAL DECOMPENSATION}

Corneal oedema, associated with subepithelial bullae and subsequent fine fibrosis and pannus formation, appears to have a variety of causes in the context of IOL complications. The corneal endothelium may be physically damaged at the time of implantations or subsequently through contact with the implant, especially in relation to prostheses sited in the anterior chamber. ${ }^{6}$ Physical abrasion of the iris, particularly where the prosthesis has rough or sharp edges, may also be a factor by provoking a sterile inflammatory reaction. However, the finding that only six of the 26 globes $(23 \cdot 1 \%)$ from patients with implant failures involving endothelial decompensation presented an associated chronic uveitis, compared with 27 of the 78 specimens $(34.6 \%)$ in which there was no corneal disturbance, does not 
suggest that inflammatory factors are of prime importance in causing endothelial damage. (The concurrence of stromal keratitis in a few instances would not normally be expected to interfere with endothelial function.) Epithelialisation and descemetisation of the anterior chamber were less common factors, as was retrocorneal fibrosis, but the contribution of raised intraocular pressure in the patients with concomitant glaucoma is not to be disregarded (15 of the 26 glaucomatous globes showing endothelial cell inadequacy).

But, whatever the reason, bullous keratopathy was the commonest type of failure following IOL insertion, and, as in the experience of Champion and Green, ${ }^{7}$ penetrating keratoplasty was the most frequent form of surgical intervention. The data are insufficient to show any differential susceptibility to corneal problems between the separate varieties of IOL.

\section{SECONDARY GLA U COMA}

The overall incidence of glaucoma in patients receiving IOLs has been estimated to vary between 0.7 and $4.3 \%$ and is the second most frequent complication in terms of requiring further surgery. ${ }^{7}$ Documented causes include occlusion of the filtration angle by peripheral anterior synechiae ${ }^{x}$ or more extensive anterior segment fibrosis, ${ }^{,}$by descemetisation, or by epithelialisation of the anterior chamber consequent on the lensectomy. ${ }^{2}$ The first of these possibilities was commonest in the present series, the iridocorneal adhesion being due in turn to inflammation, presumed trauma attributable to the haptics of the prosthesis, or retinal detachment and secondary rubeosis iridis. However, appreciable degrees of anterior segment abnormality of the type outlined can be observed in clinically successful implants, ${ }^{2}$ indicating that it is the extent of involvement that is important. Angle recession also appeared to be a significant factor in persons receiving anterior chamber IOLs. Pigment dispersion is a common finding, even in cases with good visual results, so that, while it may conceivably contribute to aqueous outflow restriction, it is unlikely to be a major factor in provoking glaucoma. The presence of an IOL does not of itself appear to cause a significant rise in intraocular pressure. ${ }^{10}$

\section{INFLAMMATION}

Suppurative endophthalmitis affected 12 of the eyes with failed implants, and in four cases in which it developed within the first three months infection introduced at the time of surgery may reasonably be blamed. Contamination of the neutralising solutions used in the days of wet-pack sterilisation by both bacteria and fungi has been incriminated in some reports. ${ }^{7112}$ In those patients in whom the postsurgical interval varied between nine months and almost four years it would seem more likely that the infection was endogenous. In such an event the infection may have been facilitated by foci of tissue damage and necrosis induced by the implant.

Minor degrees of anterior uveitis are not uncommon, even in respect of successful implants four of 18 eyes in the present study and $29.6 \%$ in an examination of 203 eyes by McDonnell et al. ${ }^{2}$ Nevertheless, over half $(56.4 \%)$ of the 85 globes with unsuccessful IOLs showed either iritis and/or cyclitis, and in six cases sterile uveitis refractory to antiinflammatory medication was the main reason for undertaking enucleation.

Reported causes of persistent uveitis include mechanical irritation, toxicity of the solutions bathing the prosthesis prior to insertion, ${ }^{4}$ allergic reactions to residual lens material in the case of extracapsular cataract extractions, and immunological disturbances involving complement.' There is evidence that complement can be activated directly by the prosthesis through the alternative pathway. ${ }^{13}$

A syndrome of uveitis with hyphaema and secondary glaucoma has been described, particularly in relation to anterior chamber IOLs, in which the initiating factor is considered to be physical damage as a result of instability or roughness of the implant. ${ }^{14}$ Sterile uveitis associated with glaucoma occurred in 23 eyes in the present study, of which 20 were anterior chamber implants, two posterior chamber implants, and one an iris-clip implant, but the available clinical information does not allow a statement on the concurrence of hyphaema.

\section{RETINAL DETACHMENT}

The reported incidence of retinal detachment in pseudophakic individuals is between $0 \cdot 2 \%$ and $2 \cdot 4 \%$ according to a recent review, ${ }^{2}$ which compares favourably with the $0 \cdot 8 \%$ to $4.9 \%$ incidence given for cataract extraction without IOL implantation. The same authors recorded four cases in their survey of 203 eyes that had largely acceptable visual results, and the present finding of seven instances of retinal detachment in an overall series of 147 specimens, most of them from unsuccessful procedures, is probably not excessive. Apple et al ${ }^{1}$ note that, while IOL implantation does not seem to be a significant aetiological factor in detachment, it can reduce the chances of successful surgery should the retina become detached for some other reason.

CONCLUSION

The success rate for intraocular lens implant procedures has increased enormously in recent years. Most of the failures in the present study related to anterior 
chamber implants (93 out of 127), but then so did the successes (14 out of 18), and it is not possible from these data to assess the relative merits of the various implant procedures.

Minor degrees of uveitis and of anterior chamber distortion appear to be compatible with clinical success, though the extremely late onset of complications in a substantial number of the patients suggests that there will always be some risk of eventual failure. This does not constitute an argument against IOL surgery, however, since it may take a lifetime (or longer!) for serious problems to arise.

\section{References}

1 Apple DC, Mamalis N, Loftfield K, et al. Complications of intraocular lenses: a historical and histopathologic review. Surv Ophthalmol 1984; 29: 1-54.

2 McDonnell PJ, Green WR, Champion R. Pathologic changes in pseudophakia. Semin Ophthalmol 1986; 1: 80-103.

3 Ashton N, Choyce DP. Pathological examination of a human eye containing an anterior chamber acrylic implant. Br J Ophthalmol 1959; 43: 577-83.

4 Ashton N, Boberg-Ans J. Pathology of an aphakic eye containing an anterior chamber implant. Br J Ophthalmol 1961; 45: 543-54.
5 Bahn CF, Sugar A. Endothelial physiology and intraocular lens implantation. J Am Intraocul Implant Soc 1981: 7: 351-64.

6 Kaufman HE, Katz JI. Effect of intraocular lenses on the corneal endothelium. Trans Ophthalmol Soc UK 1977; 97: 265-71.

7 Champion PJ, Green WR. Intraocular lenses: a histopathologic study of eyes, ocular tissues and intraocular lens obtained surgically. Ophthalmology 1985; 92: 1628-45.

8 Rowsey JJ, Gaylor JR. Intraocular lens disasters: peripheral anterior synechiae. Ophthalmology 1980; 87: 646-66.

9 Smith R. Histopathological studies of eyes enucleated after failure of intraocular acrylic lens operations. $\mathrm{Br} J$ Ophthalmol 1956; 40: 473-9.

10 Radius RL, Schultz K, Sobocinski K, Schultz RO, Easom H Pseudophakia and intraocular pressure. Am J.Ophthalmol 1984: 97: 738-42.

11 Gerding DN, Poley B, Hall WH, LeWin DP, Clark MD. Treatment of pseudomonas endophthalmitis associated with prosthetic intraocular lens implantation. Am J Ophthalmol 1979; 88: $902-8$.

12 Pettit TH, Olson RJ, Foos RY, Martin RJ. Fungal endophthalmitis following intraocular lens implantation: a surgical epidemic. Arch Ophthalmol 1980; 28: 1025-39.

13 Mondino BJ, Nagata S, Glovsky MM. Activation of the alternative complement pathway by intraocular lenses. Invest Opthalmol Vis Sci 1988; 26: 905-8.

14 Ellingson FT. Complications with the Choyce Mark VII anterior chamber lens implant (uveitis-glaucoma-hyphema). J Am Intraocul Implant Soc 1977; 3: 199-205.

Accepted for publication 2 June 1989. 